\title{
IMPROVEMENT OF PRODUCTION EFFICIENCY OF TAPERED ROLLER BEARING BY USING PLANT SIMULATION
}

\author{
Malega, P.; Kadarova, J. \& Kobulnicky, J. \\ Technical University of Kosice, Faculty of Mechanical Engineering, Institute of Management, \\ Industrial and Digital Engineering, Park Komenského 9,042 00 Kosice, Slovak Republic \\ E-Mail: peter.malega@tuke.sk, jaroslava.kadarova@tuke.sk, jan.kobulnicky@tuke.sk
}

\begin{abstract}
The aim of this article is to create a simulation model of specific production system in Plant Simulation environment. The main production program that we monitor in this article is focused on the production of tapered roller bearings. Types of produced products are wide; therefore we focus attention on a material flow of one particular dimensional type of bearing. This article is divided into five parts. In the first part there is a theoretical overview of utilization of the system module Plant Simulation. The second part is focused on product that will be used for simulation process, concretely tapered roller bearing 32303A. Third part deals with analysis of simulated system model in Plant Simulation. Fourth section is oriented on proposal of monitored production system optimization in Plant Simulation and final fifth part is about benefits evaluation of the proposed solution.

(Received in May 2017, accepted in October 2017. This paper was with the authors 1 month for 2 revisions.)
\end{abstract}

Key Words: Tapered Roller Bearing, Simulation Process, Plant Simulation, Production System, Optimization

\section{INTRODUCTION}

Continuously increasing demands and threats related to the operation of production systems require from production companies continual concentration, quick and correct decisions in an effort to consolidate and improve their market position and achieve the maximum profit [1, 2]. There are many ways and possibilities to make work more effective, respectively to maximize the use of the production system [3-5]. For the purpose of this paper, we have chosen as an optimal variant an increasingly intensified and, in practice, more frequently used concept of simulation, the use of which greatly contributes to the overall increase of competitiveness of companies.

The paper is divided into five main consecutive chapters. The first section consists from the creation of a theoretical knowledge base within the solved problem. We mainly focus on the specific Plant Simulation system module and the advantages resulting from its use in solving problems with the production systems operation. In the second chapter we analyse the specific production system whose main production program is a production of tapered roller bearings. We focus on the specific type of tapered roller bearing - 32303A and with this type we consider in creating the simulation model. The basis for the modelling is the sequence of technological operations of the selected product type. The third main section deals with the analysis of simulated system in Plant Simulation, with detailed description of inputs, operations and outputs of the selected production system. At the end of this section we show the 2D and 3D model of the monitored production system. The fourth main section is about the proposal of chosen production system optimization, while we focus on the mechanization of material flow and the goal is to increase the number of pieces produced, so we look for a part within a material flow whose optimization would make the entire production system more efficient. The final fifth main part is the evaluation of the proposal. Here we compare the statistics obtained before and after the change was introduced. If the number of produced bearings is higher and other statistics of production system are not worse, thus we have achieved the goal. 
The aim of this paper is to optimize the production of tapered roller bearings 32303A. Model of production process, which is built-up in application Plant Simulation, is used for optimization. To find the optimal variant of the production process, which would allow making for the same time the highest number of products, we used the multiple simulation of the production process. The aim of the optimization is the streamlining of production, which can be achieved by increasing the number of produced products at the same time, while reducing the unit costs of finished products.

\section{UTILIZATION OF THE SYSTEM MODULE PLANT SIMULATION}

Plant Simulation allows creating digital models, which are then used for simulation of specific conditions within the production process while changing selected parameters and characteristics of the process. Simulation of various set conditions of the production process allows optimizing before the real starting, the inputs and outputs of the production process [6].

Plant Simulation is one of the basic modules of "digital factory" package Tecnomatix from Siemens PLM (Product Lifecycle Management) software. The support for the Slovak market provides the company SOVA Digital, Inc. cooperating with the company CEIT. Tecnomatix has a number of modules and this is shown in Fig. 1 [7].

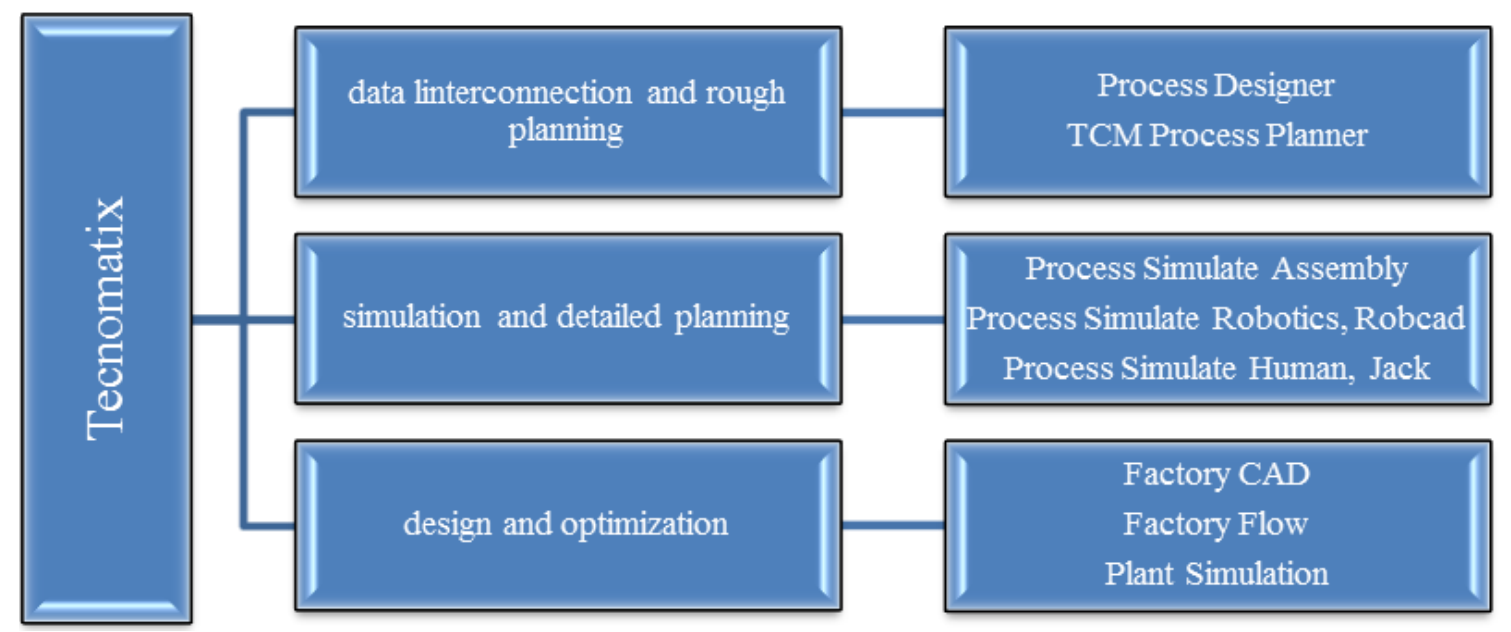

Figure 1: Modules of Tecnomatix considering the utilization [8].

During the optimization of the selected production process we decided for Plant Simulation, because of its ability to create plans or scenarios for the future in the planning phase of the project to the benefit of different production systems models. This module allows the hierarchical construction of models in 2D and 3D interface, with respect to production, storage and distribution mutually linked chains of objects. The possibilities of Plant Simulation utilization [9] are shown in Fig. 2.

During simulating the production process is evaluated the achieved output, respectively the operation of the production system during certain period, on the basis of statistical data $[10,11]$. The performance characteristics of the production systems can be summarized as follows [12-17]:

- utilization of resources,

- stock size in terms of the number of pending parts,

- machine failure statistics,

- machine blocking time,

- return on investment, 
- cost indicators of production,

- the amount of scraps,

- the number of parts that were faulty, respectively require repair,

- trouble-free operation,

- time during which work is stopped due to device inactivity,

- waiting time of the product before workplace,

- monitoring of production performance, which indicates, how many products are produced during the simulation,

- continuous production time for a particular product,

- the amount of inventories and work in process of production.

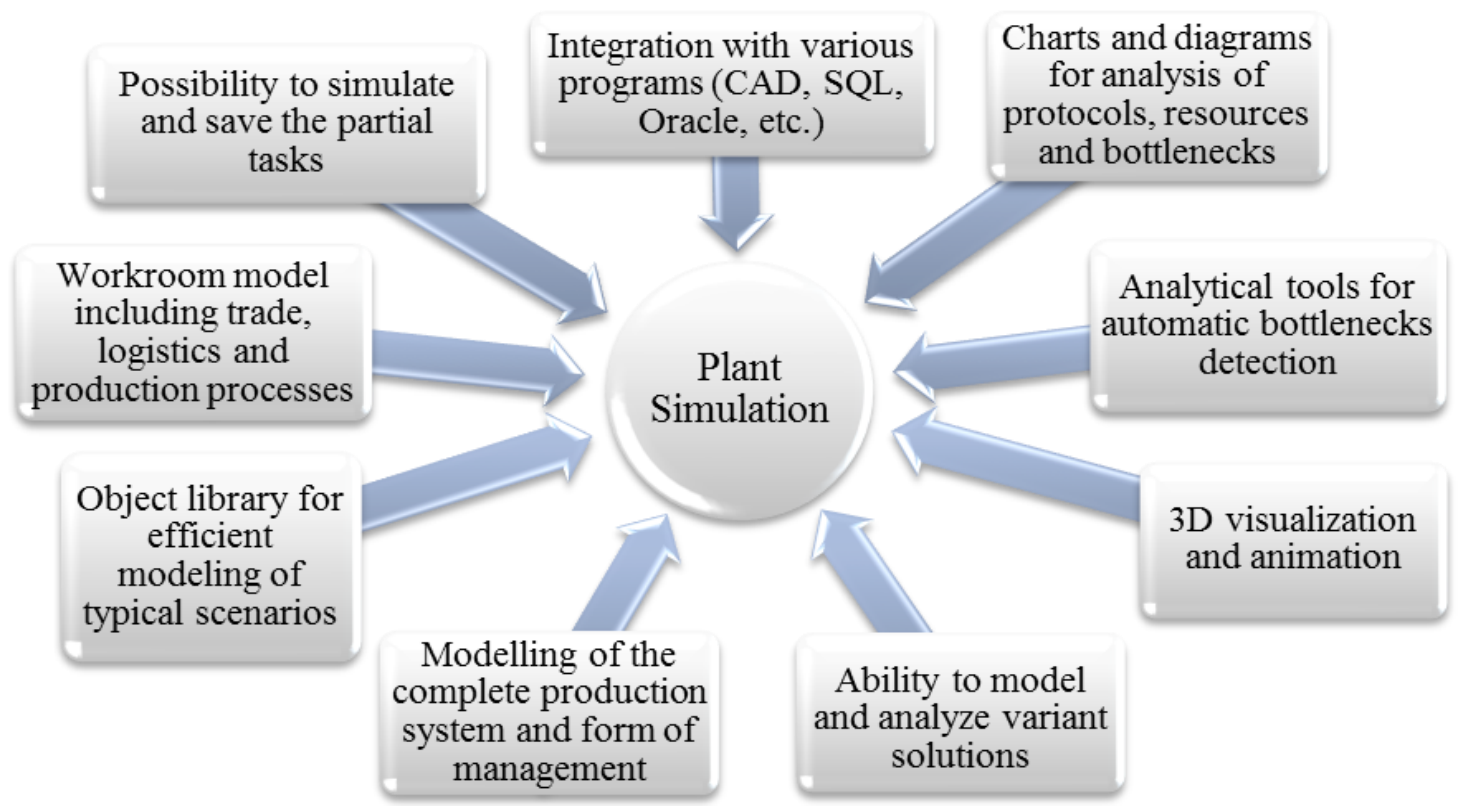

Figure 2: Examples of Plant Simulation exploitation [10].

Companies using Plant Simulation know the many benefits regarding the use of it. The benefits of using Plant Simulation are especially the following [18]:

- possibility of verifying innovative changes and strategies in the virtual interface,

- maximum utilization of production resources,

- minimizing the risk associated with an investment based on its rapid simulation testing,

- 20-60\% reduction in inventory, taking into account the size of the system,

- minimizing the investment costs of the innovated, respectively new system up to 5-20\%,

- reduction of capacities for personal and handling equipment,

- ensuring positive results and identifying the expected impacts,

- selection of the most advantageous possibilities regarding the size of systems and storage space, finding sources of problems in logistics and production sphere.

The module Plant Simulation allows identifying potential problems in time when their reparation doesn't require time-consuming and financially demanding solutions. It prevents problems in full operation $[19,20]$. The primary function of Plant Simulation is to identify and eliminate those processes that are undesirable for the selected production process, unnecessary and don't add value to the product. Preparation of the production process simulation in the pre-production phase saves time and eliminates stoppages [21-24]. Using the simulation model is also associated with cost reductions. Practice confirms that early utilization of simulation models contributes to cost savings, which is illustrated in Fig. 3. 


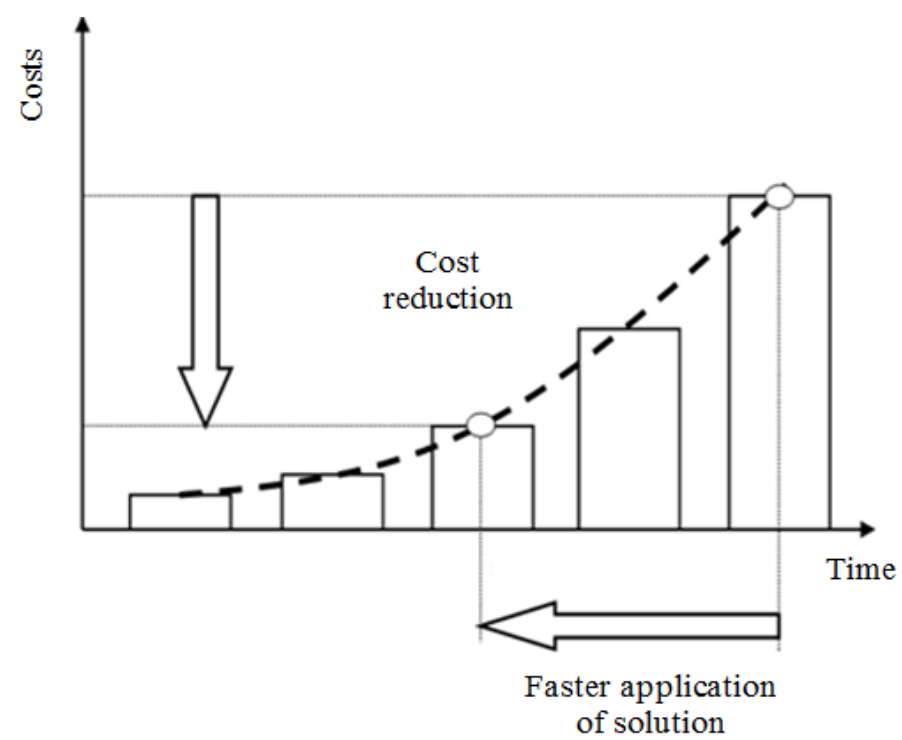

Figure 3: Cost savings resulting from the early utilization of Plant Simulation [24].

\section{PRODUCT FOR SIMULATION PROCESS}

Products we have chosen for the simulation process are tapered roller bearings. Fig. 4 shows the tapered roller bearing with its main parts. The components, from which they consist, are:

- inner ring,

- rolling element (in this case cones),

- outer ring (in the case of tapered roller bearings it is separable),

- ball cage (the purpose is to avoid contact/friction of individual cones with another cones).

Their typical characteristic, compared to other types of bearings, is the ability to transmit big axial and radial forces simultaneously [25].

Table I: Tapered roller bearing 32303A.

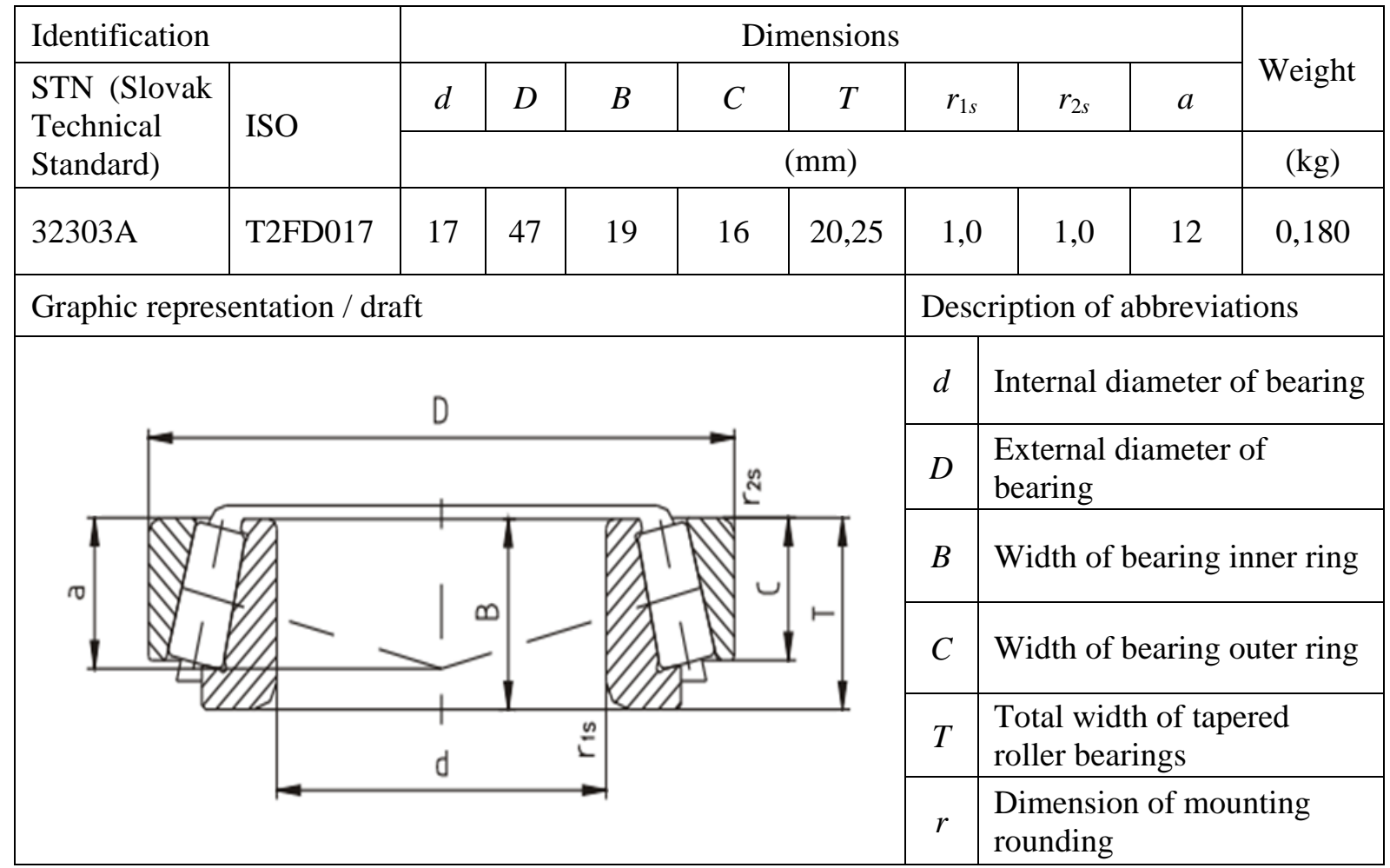


We have selected a specific type of tapered roller bearing - 32303A. It is a smaller product, but with a wide application in the mechanical engineering industry. The price of this product is about $5.25 €$. Within the production system, we will monitor the production workplaces that ensure its production and the material flow of this dimensional type of tapered roller bearing. But first, we define the basic parameters and dimensions of the product, which are listed in Table I.

We will therefore monitor the material flow focusing on:

- production flow separately of the outer and inner ring bearings,

- assembly, resp. connecting components into a single unit, i.e. finished bearings.

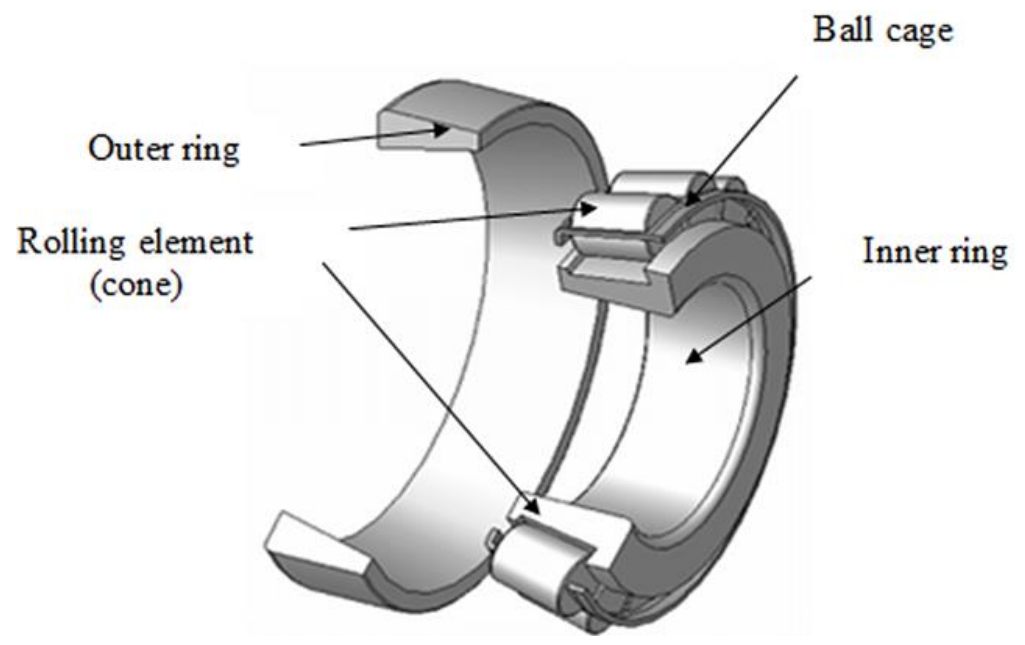

Figure 4: Main components forming tapered roller bearing.

\section{ANALYSIS OF SIMULATED SYSTEM IN PLANT SIMULATION}

For the correct simulation of the selected production system we need and use exactly two inputs, namely input of outer ring and input of inner ring. In our case, we need to use these other inputs:

- input of container for outer ring,

- input of container for inner ring,

- input of cones,

- input of ball cage.

Other mobile units that we will use during construction of the production system model include these parts:

- semi-unit,

- bearing,

- full container for outer ring,

- full container for inner ring.

After grinding of the bearing orbit, the machined pieces are stored in the containers. They don't proceed to the next operation, respectively another workstation unless they reach the capacity. This is summarized in Table II, where the quantity is given separately for the container for outer ring and especially for the container for inner ring.

Table II: Tapered roller bearing 32303A.

\begin{tabular}{|c|c|}
\hline Entity & Capacity \\
\hline Inner ring & 300 pieces \\
\hline Outer ring & 250 pieces \\
\hline
\end{tabular}


Table III: List of operations, their representation in model and time.

\begin{tabular}{|c|c|c|}
\hline Operation & $\begin{array}{l}\text { Representation } \\
\text { in the model }\end{array}$ & Time / piece \\
\hline \multicolumn{3}{|c|}{ Production of inner ring } \\
\hline Grinding of faces & Single Process & 3.54 seconds \\
\hline Surface grinding & Single Process & 3.78 seconds \\
\hline Grinding of the orbit & Parallel Process & 38 seconds \\
\hline Superfinishing & Single Process & 17 seconds \\
\hline Washing & Single Process & 0.846 seconds \\
\hline Labelling & Single Process & 3.036 seconds \\
\hline Supervision & Single Process & 4.5 seconds \\
\hline \multicolumn{3}{|c|}{ Production of outer ring } \\
\hline Grinding of faces & Single Process & 3.18 seconds \\
\hline Grinding of the orbit & Single Process & 42 seconds \\
\hline Grinding of the hole & Single Process & 40 seconds \\
\hline Grinding of relieving faces & Single Process & 35 seconds \\
\hline Superfinishing & Single Process & 25 seconds \\
\hline Washing & Single Process & 0.504 seconds \\
\hline Labelling & Single Process & 3.36 seconds \\
\hline Supervision & Single Process & 6 seconds \\
\hline \multicolumn{3}{|c|}{ Other operations } \\
\hline Assembly of the semi-finished product & Assembly & 31.2 seconds \\
\hline Removing of the semi-finished product & Single Process & 10.2 seconds \\
\hline $\begin{array}{l}\text { Fusion of the semi-finished product } \\
\text { with the outer ring }\end{array}$ & Assembly & 3 seconds \\
\hline Inspection of the mounting height & Single Process & 2.4 seconds \\
\hline Demagnetization & Line & From time to time \\
\hline Washing & Line & From time to time \\
\hline Vibration level measurement & Single Process & 6 seconds \\
\hline Packaging & Single Process & 12 seconds \\
\hline
\end{tabular}

After processing the individual product areas, i.e. grinding of faces, orbit, hole and relieving face of inner rings, respectively faces, surface and orbit of the outer rings is the final operation in the production hall superfinishing, respectively burnishing of ring orbits. After this operation, the rings in the containers are placed on the washing machine belt, where they are cleaned / washed. The entire container is washed at once.

For other operations, we don't consider with full container, but with pieces in it. We therefore need to empty the container.

Supervision will ensure that the next workplace, i.e. assembly will not receive failures, respectively components of other dimensional types, etc. Linking of the tapered roller bearing components is realized at two workplaces: "semi-unit assembly" and "bearing assembly".

For these operations, we use the "Assembly" objects again (i.e. assembly stations):

1. Into the operation "Semi-unit assembly" enter three entities (inner ring, ball cage, cones), while two separate new inputs are necessary, namely, input of cones and input of ball cage.

The output is in this case the new entity "semi-unit". We take into account that the bearing of the 32303A dimensional type contains totally 12 cones.

2. In the "bearing assembly" are combined two entities, namely the newly created entity "semi-unit" and "outer ring". The output is the finished product, i.e. "bearing".

The finished bearing then goes into demagnetizing, moving continuously along the conveyor belt, the same principle is also ensured in the washing / cleaning operation. 
Final operations are vibration measuring and packaging. In this workplace, the process of production of the tapered roller bearing is concluded and the output is a finished bearing, which arises from the simulation through the output "Drain". We want to track only the number of produced bearings, so we will no longer consider packaging in boxes.

Furthermore, in the modelling, we will assign a human factor to the modelling area. It is made for the workplaces, where their presence within the production system is necessary, respectively on the workplaces that require the machine operator.

We assign workers to these operations (one operator for one operation):

- inspection of the inner and outer ring,

- semi-unit assembly,

- semi-unit removing,

- bearing assembly,

- supervision of the assembly height,

- vibration measurement,

- packaging.

Fig. 5 shows the 2D model of the monitored production system in Plant Simulation.

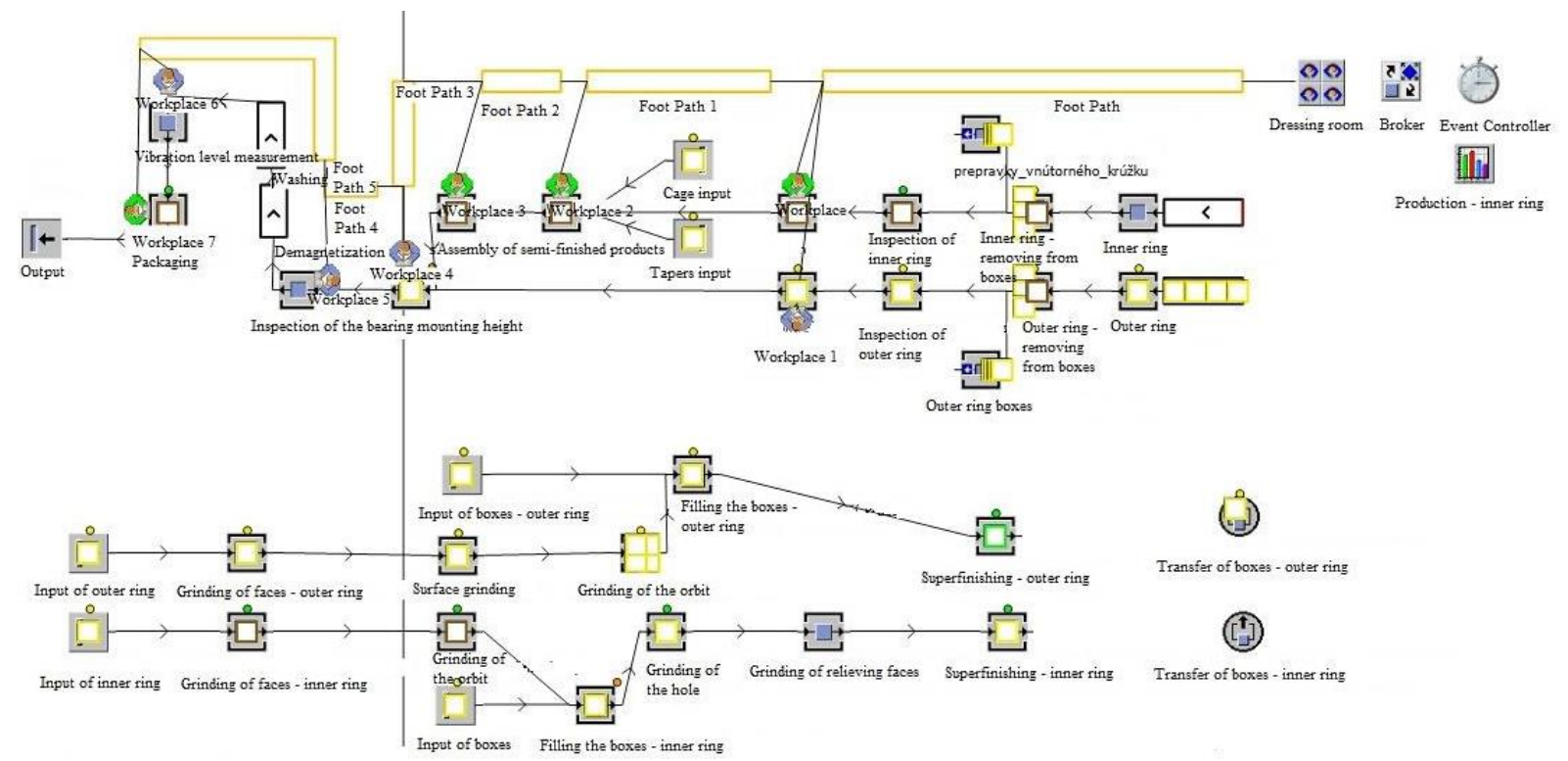

Figure 5: 2D model of the monitored production system.

In Fig. 6 is the 3D model of the monitored production system in Plant Simulation.

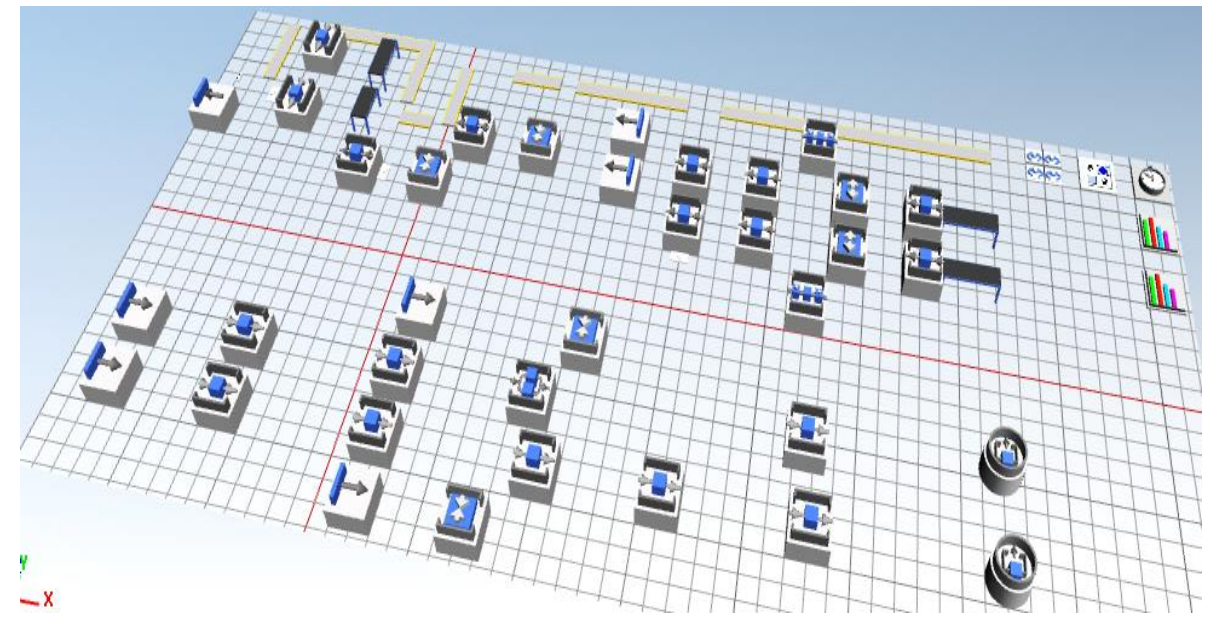

Figure 6: 3D model of the monitored production system. 


\section{PROPOSAL OF CHOSEN PRODUCTION SYSTEM OPTIMIZATION}

Our goal within production system and its optimization will be mechanization of material flow. Ultimately, we will try to increase the number of products produced at the same time, respectively find a way to increase production efficiency.

From the simulation tracking is evident that the machining time of individual areas of inner rings lasts considerably longer than the time required for the production of outer rings. The fact is that the inner ring passes through a number of grinding operations and the container also contains more pieces of semi-finished products. However, to the assembly operation, the outer rings are not received until a semi-unit is completed and the most important part there is the inner ring. The question is how to make the inner ring production process more efficient. Simultaneously our goal is to produce more products, respectively finished bearings at the same time.

As an appropriate solution of this problem we see in the replacement of the containers with a properly designed conveyor system. This would ensure continuous and rhythmical transport of pieces between workplaces. As well as, employees would save time; respectively they could concentrate on other more useful activities than transferring these transport units from machine to machine. We therefore think as follows. After machining orbit of rings, the individual pieces instead of being loaded into this handling unit would be directed to the conveyor belt, with this would be moved in sequence to the next workstation, i.e. grinding of the hole. Similarly, we would solve the location of the conveyor between the workplaces grinding of the hole and grinding of relieving faces, and from there to the superfinishing operation. In Table IV is the overview of the conveyor application.

Table IV: Overview of the conveyor application.

\begin{tabular}{|l|c|}
\hline \multicolumn{1}{|c|}{ Objects, resp. operations } & Conveyor length $(\mathrm{m})$ \\
\hline Grinding of the orbit and the hole & 3 \\
\hline Grinding of the hole and the relieving faces & 3 \\
\hline Grinding the relieving faces and superfinishing & 4 \\
\hline
\end{tabular}

After finishing last operation within surface treatment on the inner ring, we would consider using containers, because washing is set in the way that the rings are all cleaned at once by moving them over the machine belt.

We have chosen belt conveyor, which is one of the most widely used transport equipment, because it has got application in various industries. Belt conveyors are able to transport to short, medium and long distances. In the decision, we considered the fact what material, or semi-finished product will be transported and under what conditions this process will be implemented.

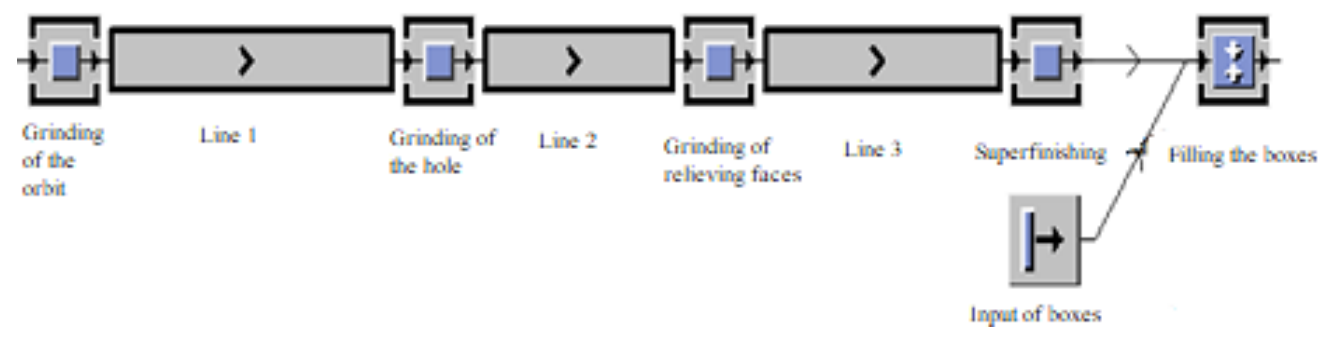

Figure 7: Part of the model after the change, i.e. loading the conveyor into the model.

In our case, we work with dimensionally small products of circular type of construction. Therefore, we must count with sealing on the sides, respectively with the lateral guide on the 
conveyor sides. This is performed due to the fact that the transported semi-finished products don't fall down during the movement. We have to ensure that they don't roll away around the conveyor area, respectively have a stable position during their movement from one operation to another operation. In Fig. 7 is a part of the production system model after the introduction of conveyor belt into the modelling area and in Fig. 8 is a belt conveyor shown in 3D.

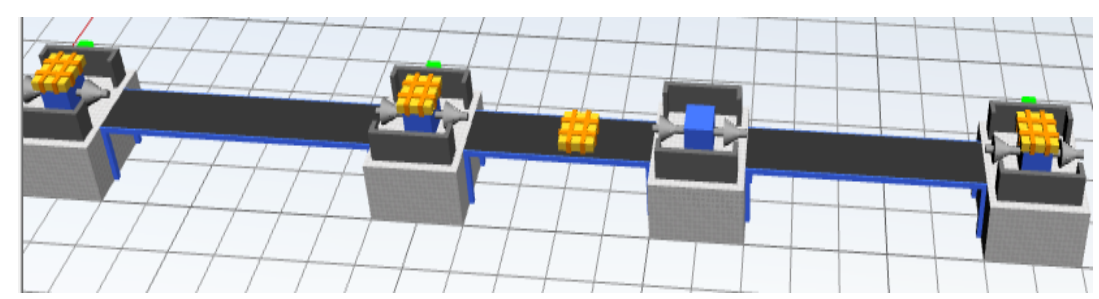

Figure 8: Belt conveyor in 3D mode.

Fig. 9 shows the 2D model of the monitored production system in Plant Simulation after the changes that were described above.

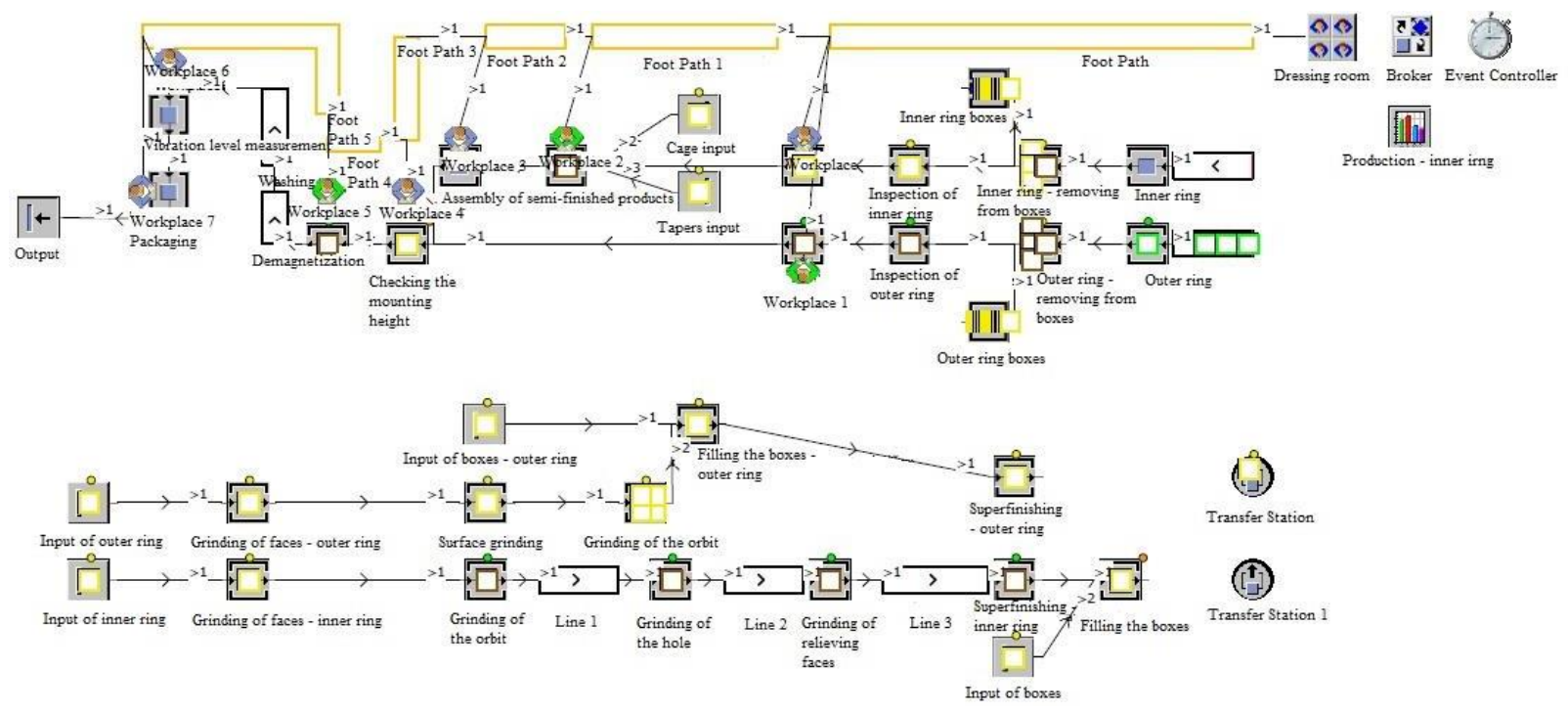

Figure 9: 2D model of production system after insertion of conveyors.

\section{BENEFITS EVALUATION OF THE PROPOSED SOLUTION}

Our goal was to achieve a situation in which the production of a particular bearing dimensional type would be made more efficient during the observed period (one day).

After the simulation, we will generate a statistical table with the necessary data. In our particular case, we will be most interested in the "Throughput" item. It records the number of products as the "output", respectively the number of products that were produced during the simulation. As we have just tried to maximize this value as the optimization criterion, it is crucial information for us whether we have met the goal that has been set.

Table V: Statistical data from the simulation before introducing the proposed change.

\begin{tabular}{|c|c|c|c|c|c|c|c|c|c|}
\hline Object & Name & $\begin{array}{l}\text { Mean } \\
\text { Life } \\
\text { Time }\end{array}$ & 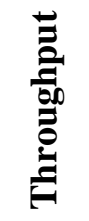 & TPH & 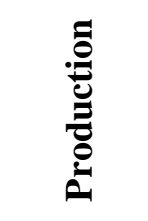 & 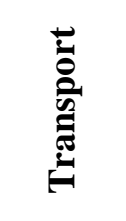 & 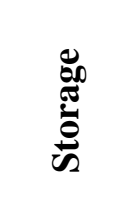 & $\frac{\mathscr{E}}{\stackrel{D}{\sigma}}$ & : \\
\hline Output & Bearing & 1:37.9339 & 1094 & 46 & $95.26 \%$ & $4.74 \%$ & $0.00 \%$ & $23.89 \%$ & - \\
\hline
\end{tabular}


In the first case, i.e. even with the use of the containers as a handling unit, the number of produced bearings from the data of the statistical table is exactly 1094 pieces. Other generated items are listed in Table $\mathrm{V}$.

By introducing belt conveyors during the unchanged duration of simulation, 1806 products were produced, that is about 712 taper roller bearing pieces more than in the first case (Table VI). The main reason is to ensure a more fluent production of inner rings in the production hall between the individual operations of surfaces grinding. Therefore, about two more complete containers were produced than in first case.

Table VI: Statistical data from the simulation after introducing the proposed change.

\begin{tabular}{|c|c|c|c|c|c|c|c|c|c|}
\hline Object & Name & $\begin{array}{c}\text { Mean Life } \\
\text { Time }\end{array}$ & 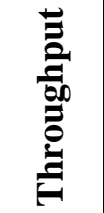 & TPH & 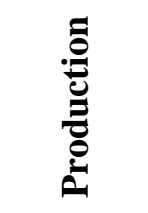 & 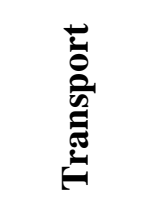 & 葡 & 兰 & : \\
\hline Output & Bearing & $1: 12.5897$ & 1806 & 75 & $88.04 \%$ & $11.96 \%$ & $0.00 \%$ & $32.24 \%$ & 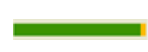 \\
\hline
\end{tabular}

We will consider already about work performance of individual machines, among which we want to place the handling equipment, i.e. workplaces that work on the inner ring. We will compare their performance before and after the conveyor belt is introduced. We will look at the results of "Chart", i.e., graphs used in both simulation models.

In Fig. 10 is a comparison of machine efficiency (before and after conveyors implementation), which track utilization on operations: grinding of the orbit, grinding of the whole, grinding of relieving faces and superfinishing.

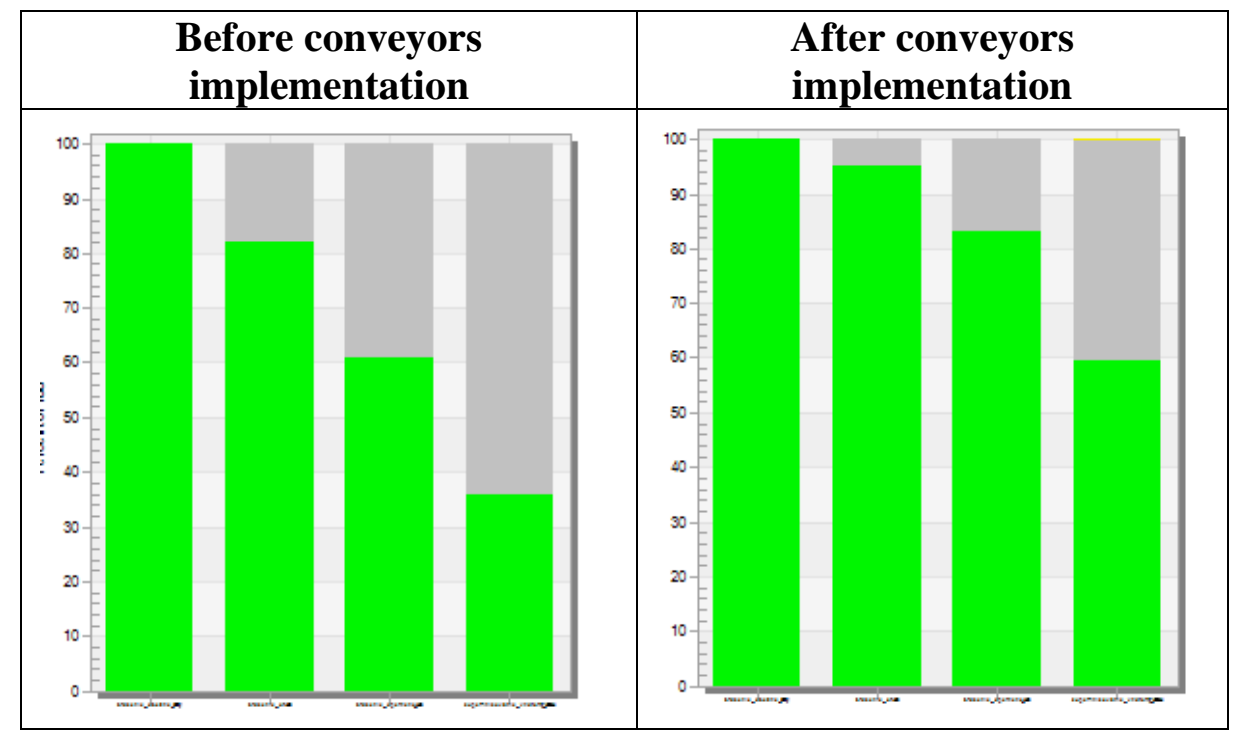

Figure 10: Comparison of machine efficiency.

In the graphs, we follow the ratio of green and grey colour. Green colour represents the machine work; on the other hand grey colour represents waiting. After optimization, the work vs. waiting ratio has slightly changed which means that the production on these devices after the optimization runs continuously.

By introducing conveyor belts we achieved:

- increasing the number of produced bearings during the monitored period,

- continuous production. 


\section{CONCLUSION}

The primary objective of each company in the conditions of the current, most turbulent and complex market environment has to be support and stimulation of development, respectively productivity and competitiveness growth [26, 27]. The companies are forced to continually improve and adapt to the demands of hard competition, respectively to meet the expectations and needs of their customers [28]. The basis for this success lies in a properly and efficiently implemented production system. There are many resources and possibilities to make it more efficient [29]. In this paper, we have chosen as the best option in practice the increasingly frequently used simulation. We used the simulation module Plant Simulation, which is the tool of dynamic simulation, and is also the basis of the paper.

We have tried to increase the production of tapered roller bearings. Based on the simulation, we decided to focus on a particular part of the material flow, namely the production of one of the bearing elements - the inner ring. So our goal was to find a solution that allows producing more pieces for the same time. Ultimately, the more inner rings get to the assembly, the more bearings are produced. In the fourth main section, this was dedicated to proposal of chosen production system optimization, we chosen a solution in the form of belt conveyor with which we have replaced boxes.

We brought the belt conveyors to the model area of this model for the necessary design verification. On the basis of the statistics we generated after the simulation ended, we could compare the results before and after the proposed change was introduced. Due to the use of conveyor belts, the number of taper roller bearings has increased by two more full boxes.

The aim of the article was to evaluate the selected production system and based on the obtained results from the simulation, to propose actions/solutions that would increase the production capacity, respectively would increase efficiency of production process for the product tapered roller bearing 32303A.

From the results of final evaluation we conclude that the proposal we presented and verified in the Plant Simulation environment can be considered as reasonable and fulfil the purpose with which we performed the simulation.

\section{ACKNOWLEDGEMENT}

This article was created by implementation of the grant Project VEGA 1/0741/16 "Controlling innovation of the industrial companies for the sustaining and improving their competitiveness", and "Project Digital economy in the Industry 4.0 context".

\section{REFERENCES}

[1] Gingu (Boteanu), E. I.; Zapciu, M.; Cavalieri, S. (2017). Production systems flow modelling using decomposition method and required buffers, International Journal of Simulation Modelling, Vol. 16, No. 2, 207-218, doi:10.2507/ijsimm16(2)2.367

[2] Yilmaz, O. F.; Cevikcan, E.; Durmusoglu, M. B. (2016). Scheduling batches in multi hybrid cell manufacturing system considering worker resources: A case study from pipeline industry, Advances in Production Engineering \& Management, Vol. 11, No. 3, 192-206, doi:10.14743/apem2016.3.220

[3] Yang, B.; Chen, W.; Lin, C. (2017). The algorithm and simulation of multi-objective sequence and balancing problem for mixed mode assembly line, International Journal of Simulation Modelling, Vol. 16, No. 2, 357-367, doi:10.2507/ijsimm16(2)co10

[4] Zacharia, P. T.; Nearchou, A. C. (2012). Multi-objective fuzzy assembly line balancing using genetic algorithms, Journal of Intelligent Manufacturing, Vol. 23, No. 3, 615-627, doi:10.1007/ $\underline{\text { s10845-010-0400-9 }}$ 
[5] Li, C.; Liu, F.; Cao, H.; Wang, Q. (2009). A stochastic dynamic programming based model for uncertain production planning of re-manufacturing system, International Journal of Production Research, Vol. 47, No. 13, 3657-3668, doi:10.1080/00207540701837029

[6] Dlouhy, M. (2007). Simulation of Business Processes, Computer Press, Brno (in Czech)

[7] Kosturiak, J.; Gregor, M.; Micieta, B.; Matuszek, J. (2000). Design of production systems for the $21^{\text {st }}$ century, University of Žilina, Žilina

[8] Straka, L. (2005). New trends in technology system operation, Proceedings of the $7^{\text {th }}$ Conference with international participation in Prešov, 385-388

[9] Davenport, T. H. (1992). Process innovation: Reengineering work through information technology, Harvard Business School Press, Boston

[10] Hudacinova, M. (2016). Optimization of production system in the Plant Simulation, Diploma work, SjF TU Košice, Košice

[11] Chen, Y. X. (2016). Integrated optimization model for production planning and scheduling with logistics constraints, International Journal of Simulation Modelling, Vol. 15, No. 4, 711-720, doi:10.2507/ijsimm15(4)CO16

[12] Bellgran, M.; Safsten, E. K. (2010). Production Development: Design and Operation of Production Systems, Springer Science \& Business Media, London

[13] Marasova, D.; Cehlar, M.; Husakova, N. (2015). Procedure of creation and design of simulation model of calcined ore conveyance, $5^{\text {th }}$ International Symposium Mining and Environmental Protection, 9-14

[14] Kubis, J. (2007). Business processes and their modelling, Ekonom, Bratislava (in Czech)

[15] Bangsow, S. (2010). Manufacturing Simulation with Plant Simulation and SimTalk: Usage and Programming with Examples and Solutions, Springer-Verlag, Berlin

[16] Fabian, S.; Straka, L. (2008). Operation of production systems, Proceedings of FVT TU of Košice established in Prešov, 252-255

[17] Teplicka, K. (2016). Quantitative models of operational research, VŠB-TU Ostrava, Ostrava

[18] Grasseova, M. (Ed.). (2008). Process management, Computer Press, Brno (in Czech)

[19] Kovac, M.; Kovac, J. (2011). Innovative design of production processes and systems, SjF TUKE, Košice

[20] Sutaj-Estok, A.; Liberko, I.; Sirkova, M. (2012). Process management in relation to the systems thinking, Management 2012: Research management and business in the light of practical needs, 214-218

[21] Skorik, P.; Stefanik, A. (2010). Simulation of Manufacturing Systems - an excellent opportunity to present the achieved results, Productivity and Innovation, Vol. 11, No. 1, 12-15

[22] Kucharcikova, A.; Tokarcikova, E.; Durisova, M.; Jackova, A.; Kozubikova, Z.; Vodak, J. (2011). Effective production, Computer Press, Brno (in Czech)

[23] Tomek, G.; Vavrova, V. (2000). Production management, Grada Publishing, Praha (in Czech)

[24] Tucek, D.; Bobak, R. (2006). Production systems, UTB in Zlin, Zlin (in Czech)

[25] Centobelli, P.; Cerchione, R.; Murino, T.; Gallo, M. (2016). Layout and material flow optimization in digital factory, International Journal of Simulation Modelling, Vol. 15, No. 2, 223-235, doi:10.2507/ijsimm15(2)3.327

[26] Zairi, M.; Sinclair, D. (1995). Business process re-engineering and process management: A survey of current practice and future trends in integrated management, Business Process Reengineering \& Management Journal, Vol. 1, No. 1, 8-30, doi:10.1108/14637159510798248

[27] Tako, A. A.; Robinson, S. (2012). The application of discrete event simulation and system dynamics in the logistics and supply chain context, Decision Support Systems, Vol. 52, No. 4, 802-815, doi:10.1016/j.dss.2011.11.015

[28] Xia, B.; Xi, L.; Zhou, B.; Du, S. (2013). An efficient analytical method for performance evaluation of transfer lines with unreliable machines and finite transfer-delay buffers, International Journal of Production Research, Vol. 51, No. 6, 1799-1819, doi:10.1080/ $\underline{00207543.2012 .713137}$

[29] Svoboda, T.; Gaffova, Z.; Rajnoha, R.; Satanova, A.; Kminiak, R. (2017). Bending forces at the proportionality limit and the maximum - technological innovations for better performance in wood processing companies, BioResources, Vol. 12, No. 2, 4146-4165, doi: $10.15376 /$ biores.12.2.4146-4165 